\title{
DEVELOPMENT OF ARBUSCULAR MYCORRHIZAL FUNGI IN THE PRESENCE OF DIFFERENT PATTERNS OF Trifolium repens SHOOT FLAVONOIDS
}

\author{
José Martín Scervino, María Alejandra Ponce², Ivana Della Monica ${ }^{2}$, Horst \\ Vierheilig $^{3,4}$, Juan Antonio Ocampo ${ }^{4 *}$ and Alicia Godeas ${ }^{1}$ \\ ${ }^{1}$ Departamento de Biodiversidad y Biología Experimental, ${ }^{2}$ CIHIDECAR-CONICET; \\ Departamento de Química Orgánica, Facultad de Ciencias Exactas y Naturales, Universidad de \\ Buenos Aires, Pabellón II, Buenos Aires, Argentina. ${ }^{3}$ Institut für Pflanzenschutz, Department für \\ Angewandte Pflanzenwissenschaften und Pflanzenbiotechnologie, Universität für Bodenkultur \\ Wien, Peter-Jordan-Strasse 82, 1190 Wien, Austria. ${ }^{4}$ Departamento de Microbiología, Estación \\ Experimental de Zaidín, CSIC, Prof. Albareda 1, E-18008 Granada, Spain. *Corresponding \\ author: jocampo@eez.csic.es
}

\begin{abstract}
We tested the effects of the flavonoid 3-methoxi-5,6,7,8-hydroxy-4'hydroxy flavone (NMHTV) isolated from shoots of non arbuscular mycorrhizal (AM) inoculated clover, and of the flavonoids 5,6,7,8-hydroxy-3-methoxy flavone (MH-1); 5,6,7,8-hydroxy-4'hydroxy flavone (MH-2); and 5,7-hydroxy-3,4'-methoxy flavone (MH-3); isolated from AM clover (Trifolium repens) shoots, on spore germination, hyphal length, hyphal branches and the number of cluster of auxiliary cells or the number of secondary spores (Presymbiotic stage) and on the number of entry points and the percentage of AM colonized root of tomato (Lycopersicum esculentum) by the AM fungi Gigaspora rosea, Giaspora margarita, Glomus mosseae and Glomus intraradices (Symbiotic stage). Non significant effects of the flavonoids isolated from the shoot of mycorrhizal colonized clover on the presymbiotic and symbiotic stages of Gigaspora and Glomus endophytes were found. The flavonoid NMHTV isolated from non AM clover shoot, did not affect the percentage of germination of spores but significantly increased $(\mathrm{P}<0.05)$ the other steps of the presymbiotic stage of Gi. margarita spores when $2 \mu \mathrm{M}$ concentration was used. The symbiotic stage of Gi. margarita was also significantly increased when $2 \mu \mathrm{M}$ of the flavonoid NMHTV was applied. This flavonoid had no effect on the presymbiotic development of $G$. mosseae, $G$. intraradices and Gi. rosea except when $8 \mu \mathrm{M}$ concentration was used, which inhibited the hyphal length of Gi. rosea. These results suggest the possible implication of the flavonoid NMHTV in the susceptibility of tomato roots to the AM formation by Gi. margarita. The absence of stimulation of the AM presymbiotic and symbiotic stages in tomato by exogenous application of the newly synthesized flavonoids $\mathrm{MH}-1, \mathrm{MH}-2$, and $\mathrm{MH}-3$, in clover shoots after AM colonization, indicated that the autorregulation of the AM symbiosis can be, at least partially, due to the disappearance of flavonoids in AM colonized plants that stimulated the AM symbiosis.
\end{abstract}

Keywords: Arbuscular mycorrhizas, flavonoids, signal molecules, symbiosis 


\section{INTRODUCTION}

The colonization of plant root by arbuscular mycorrhizal (AM) fungi involves a molecular dialogue between plant and AM fungi (Harrison, 1998). This dialogue starts in the presymbiotic stage of the fungi and might be regulated by secondary metabolites from the plant before that the fungus enters into the root. Flavonoids are secondary plant metabolite presents in most plants, are components of the soil rhizosphere and play an important role in many plant microbial interactions (Phillips and Tsai, 1992; Akiyama et al., 2002; Larose et al., 2002; Vierheilig et al., 2002).

Most studies on the effect of AM symbiosis on plant physiology have been focused to changes produced in roots but not in shoots. However, AM symbiosis have systemic influence in several plant processes which will affect the development of the symbiosis such as signals molecules implicated in plant susceptibility to AM formation, in autoregulation of AM symbiosis or in plant defence response in AM symbiosis (Martin et al., 2002; Vierheilig and Piche, 2002; Taylor and Harrier, 2003; Vierheilig et al., 2003).

Flavonoids from plants are molecules that can be involved in the colonization of plant root by AM fungi and play an important role in the presymbiotic (Spore germination, hyphal length, hyphal branching and formation of cluster of auxiliary cells or secondary spores) and symbiotic stages (Formation of entry points and root colonization) of the AM fungi development (Morandi, 1996; Vierheilig et al., 1998). The establishment of the AM interaction is localized into the roots; however, the AM interaction produced physiological and molecular changes no only in the root but also in the shoot (Poulton et al., 2002; Taylor and Harrier, 2003). In fact, quantitative and qualitative changes in the pattern of flavonoids into the shoots of clover when these plants were inoculated with Glomus intraradices were observed (Ponce et al., 2004). In shoot of clover without mycorrhiza only the flavone 3-methoxi5,6,7,8-hydroxy-4'hydroxy flavone (NMHTV) was isolated (Ponce et al., 2004). When clover was colonized with $G$. intraradices the 3-methoxy-5,6,7,8hydroxy-4'hydroxy flavone disappear from the shoot and the flavones 5,6,7,8hydroxy-3-methoxy flavone (MH-1); 5,6,7,8-hydroxy-4'-hydroxy flavone (MH-2); and 5,7-hydroxy-3,4'-methoxy flavone (MH-3) were newly synthesized (Ponce et al., 2004). Formation of these plant flavonoids by mycorrhizal fungi might be involved in the enhanced resistance of mycorrhizal plants against penetration of roots by mycorrhizal fungus or soil-borne plant pathogens (Larose et al., 2002).

Contradictory results about the positive and negative influence of flavonoids on the AM fungal development have been obtained (Tsai and Phillips, 1991; Bécard et al., 1992; Chabot et al., 1992; Baptista and Siqueira, 1994; Poulin et al., 1997; Vierheilig et al., 1998), and some of these compounds can increase the level of AM colonization of roots (Siqueira et al., 1991; Kape et al., 1992; Morandi et al., 1992; Vierheilig et al., 1998).

The complex actions of the flavonoids on the AM fungi depend on the type and concentration of flavonoid, on the genera or even the specie of arbuscular endophytes and on the stage of the AM development (Vierheilig et al., 1998).

There is not knowledge about the effect of the flavonoids described 
above on development of AM fungi. The new synthesis and suppression of some flavonoids in clover shoots colonized by the AM fungus $G$. intraradices suggests a possible role of these plant molecules in the regulation process of the AM symbiosis (Vierheilig and Piche, 2002). In this work we study the effects of flavonoids isolated from AM and nonAM inoculated clover shoot on the presymbiotic stage of the Giaspora rosea, Giaspora margarita, Glomus mosseae and $G$. intraradices and on the number of entry points and the percentage of root colonization of tomato by these AM fungi.

\section{MATERIAL AND METHODS}

\section{Isolation and identification of flavonoids}

The flavonoid 3-methoxi-5,6,7,8hydroxy-4'hydroxy flavone (NMHTV) was isolated from shoot of non-inoculated clover (Trifolium repens), and the flavonoids $\mathrm{MH}-1, \mathrm{MH}-2$ and $\mathrm{MH}-3$ from AM inoculated clover shoot as described by Ponce et al. (2004).

\section{Effect of flavonoids on AM spores}

Flavonoids were tested on Gigaspora rosea (BEG 9), Gi. margarita (J7) from Buenos Aires Fungal Collection (BAFC), Glomus mosseae (BEG 12) and $G$. intraradices (DAOM 197198) spores in 9 $\mathrm{cm}$ diameter Petri dishes. Spores of Gi. margarita Becker and Hall were isolated from Ciudad Universitaria soil (Fracchia, 2002), in the province of Buenos Aires (Argentina) and morphologically identified (Bentivenga and Morton, 1995).

Flavonoids were dissolved in absolute ethanol to obtain $4 \mathrm{mM}$ stock solutions. Thereafter, flavonoids were filtered through a disk of filter paper and sterilized twice by filtration through a $0.20 \mu \mathrm{m}$ Millipore membrane (Filtropur $\mathrm{S}$, SARSTEDT), and transferred to $10 \mathrm{ml}$ of $10 \mathrm{mM}$ 2-(N-morpholin) ethane sulphonic acid (MES) buffer (pH 7) plus $0.04 \mathrm{~g}$ of Gel-Gro (ICN Biochemicals, Aurora, Ohio, USA). The concentration of $0.05 \%$ ethanol was selected because test had shown it did not affect germination and hyphal growth from Gigaspora and Glomus spores (Whereas $0.1 \%, 0.5 \%$ and $1 \%$ did). The flavonoids dissolved in absolute ethanol were added to $10 \mathrm{ml}$ of Gel-Gro at a final concentration of $0.5,2$ and $8 \mu \mathrm{M}$ in $0.05 \%$ ethanol. Flavonoid concentrations of $0.5,2$ and $8 \mu \mathrm{M}$ were selected for testing based of effects previously reported (Morandi, 1996; Vierheilig et al., 1998). Petri dishes with $0.05 \%$ ethanol or without ethanol were used as control.

Spores of Gi. rosea, Gi. margarita, G. intraradices and sporocarps of $G$. mosseae were isolated by wet sieving the soil (Gerdemann, 1955), from a clover pot culture (Trifolium repens) and were stored in water at $4^{\circ} \mathrm{C}$ until used. The spores of $G$. mosseae were obtained by dissecting the sporocarps. Spores of Gi. rosea, Gi. margarita, $G$. mosseae and $G$. intraradices were surface-sterilized (Mosse, 1962). The spores were selected with the aid of a stereomicroscope and aseptically transferred to a $5 \mathrm{~cm}$ diameter Petri dish with $10 \mathrm{ml}$ of Gel-Gro. In the experiments ten plates replications and 10 controls of each treatment were prepared. Ten surface sterilized spores per Petri dish of Gi. rosea, Gi. margarita, G. mosseae or $G$. intraradices were placed onto the surface of the medium (A hundred spores per treatment).

The Petri plates were sealed to reduce dehydratation and contamination risks and were then incubated in the dark at $25^{\circ} \mathrm{C}$ 
for 2 weeks. The percentage spore germination, hyphal length $(\mathrm{mm})$, hyphal branches, the number of cluster of auxiliary cells of Gigaspora spores and the number of secondary spores of $G$. mosseae were determined. Hyphal length of germinated spores was assessed using the gridline intersect method (Marsh, 1971).

\section{Effect of flavonoids on AM root colonization}

The effect of the flavonoids of clover plants shoots on the number of AM entry points and percentage of root colonization of tomato (Lycopersicum esculentum) by Gi. rosea, Gi. margarita, G. mosseae and $G$. intraradices spores were tested in $5 \mathrm{~cm}$ diameter Petri dishes using a monosporic culture technique (Fracchia et al., 2001). One surface sterilized spore was transferred with a sterilized Pasteur capillary pipette to a $5 \mathrm{~cm}$ diam Petri dish with $10 \mathrm{ml}$ of $10 \mathrm{mM}$ MES buffer (pH 7) plus $0.04 \mathrm{~g}$ of Gel-Gro. Petri dishes were incubated at $25^{\circ} \mathrm{C}$ for $8 \mathrm{~d}$ and spore germination and hyphal development were observed under a binocular microscope. Petri dishes contaminated with other microorganisms were discarded. Petri dishes with hyphal length about $5 \mathrm{~mm}$ for Glomus or $2 \mathrm{~cm}$ for Gigaspora strains were selected.

Tomato seedlings were grown in $5 \mathrm{~cm}$ diameter Petri dishes with $10 \mathrm{ml}$ of autoclaved $\left(120^{\circ} \mathrm{C}, 20 \mathrm{~min}\right)$ vermiculiteperlite mixture $(1: 1, \mathrm{~V}: \mathrm{V})$. The vermiculite and perlite were previously sieved through $500 \mu \mathrm{m}$ mesh. Seeds were surface sterilised with $10 \%$ sodium hypochlorite for $2 \mathrm{~min}$ and 1 seed was sown on each vermiculite:perlite Petri dish. Plants were grown in a chamber with Sylvania incandescent and coolwhite lamp 400-700 nm, with a 16/8 h day/dark cycle at $25 / 19^{\circ} \mathrm{C}$ and $50 \%$ relative humidity. The flavonoids and the content of a vermiculite-perlite dish with 2 week-old tomato seedling was transferred at the same time onto the GelGro medium with the germinated spore. The hyphal development was observed every $2 \mathrm{~d}$ through the bottom of the Petri dish under the binocular microscope. All plants inoculated with single germinated spores developed mycorrhizas. With this system non-destructive observation of hyphal development and hyphal contact of AM fungi with the plant root was possible.

Plants were harvested and the root system was cleared and stained (Phillips and Hayman, 1970). Material from each replicate was cut into $1 \mathrm{~cm}$ segments that were mixed and repeatedly subdivided to yield random samples of 50 root segments. These were mounted on slides and examined under a compound microscope at x160 magnifications and the number of entry points (appresoria) per $30 \mathrm{~cm}$ of root was estimated (Ocampo et al., 1980). The percentage of root colonization was measured by the line intersect method (Giovannetti and Mosse, 1980).

In the experiment 20 replicates per treatment and controls were used. Ten replicates per treatment and control plants were harvested when hyphal contact of the AM fungi with the plant root was observed (usually about 2 weeks after seedling transplanting), and the number of entry points was assessed. The rest of the plants were harvested 6 weeks after transplanting and the percentage of root colonization was measured.

\section{Statistical treatments}

Experimental data were statistically analysed by ANOVA and Tukey's test 
$(\mathrm{P}<0.05)$. Percentage data were subjected to arcsine transformation before analysis. Each experiment was repeated at least twice. Statistical analyses were conducted in SPSS software, version 11.0 (SPSS Inc., 1989-2001).

\section{RESULTS}

Microscopic observations of stained roots showed AM fungi only in AM inoculated clover plants, where $80 \pm 9 \%$ of root were colonized.

Under our experimental conditions the dry weights of tomato shoots grown in Petri dishes were similar $(125 \pm 18 \mathrm{mg})$ in all treatments. There were no significant effects of the flavonoids $\mathrm{MH}-1, \mathrm{MH}-2$ and $\mathrm{MH}-3$, isolated from the shoot of clover colonized by AM fungi, on percentage of spore germination, hyphal length and number of hyphal branches of Gi. rosea, Gi. margarita, G. mosseae and $G$. intraradices at any of the concentrations tested. No significant effect of these flavonoids on number of clusters of auxiliary cells of Gi. rosea and Gi. margarita, and on the number of secondary spores of $G$. mosseae and $G$. intraradices were also found.

In presence of the flavonoids $\mathrm{MH}-1$, $\mathrm{MH}-2$ and $\mathrm{MH}-3$, the values for percentage of spore germination were $46 \pm 5 \%$ for Gigaspora and $60 \pm 5 \%$ for Glomus. The hyphal length was $30 \pm 5 \mathrm{~mm}$ for Gigaspora and $13 \pm 2 \mathrm{~mm}$ for Glomus. The number of hyphal branches was $5 \pm 1$ for Gigaspora and $17 \pm 3$ for Glomus. The number of clusters of auxiliary cells was $0.6 \pm 0.1$ for Gigaspora and the number of secondary spores was $3.5 \pm 0.4$ for Glomus.

There were non significant effects of the flavonoids $\mathrm{MH}-1, \mathrm{MH}-2$ and $\mathrm{MH}-3$, on the number of entry points and the percentage of tomato root colonized by these endophytes. The values for the number of entry points were $9 \pm 2$ for Gigaspora and $30 \pm 5$ for Glomus and for the percentage of AM root colonization were $12 \pm 2 \%$ for Gigaspora and 35 $46 \%$ for Glomus.

The flavonoid NMHTV isolated from shoot of clover noninoculated with AM fungi did not affect the percentage of germination of Gi. rosea, Gi. margarita, $G$. mosseae and $G$. intraradices spores (Data not shown). The concentration of 8 $\mu \mathrm{M}$ of NMHTV inhibited the hyphal length of $\mathrm{Gi}$. rosea. However, the presence of $2 \mu \mathrm{M}$ of NMHTV significantly increased the hyphal length of Gi. margarita. The hyphal length of $G$. mosseae and $G$. intraradices was not affected by NMHTV at any of the concentrations tested (Fig 1).

The flavonoid NMHTV did not affect on the number of hyphal branches of $G i$. rosea, $G$. mosseae or $G$. intraradices spores, while the number of hyphal branches of $G i$. margarita was significantly increased when $2 \mu \mathrm{M}$ of NMHTV was applied (Fig. 2). The application of $2 \mu \mathrm{M}$ of the flavonoid NMHTV increased the number of clusters of auxiliary cells of Gi. margarita, while this flavonoid did not have effects on the number of clusters of auxiliary cells of $G i$. rosea (Fig. 3).

The number of secondary spores of $G$. mosseae was unaffected by the application of NMHTV (Fig. 3). The number of entry points and the percentage of tomato root colonized by Gi. margarita significantly increased when $2 \mu \mathrm{M}$ of the flavonoid NMHTV was applied (Fig. 4 and 5). 
Gi. rosea

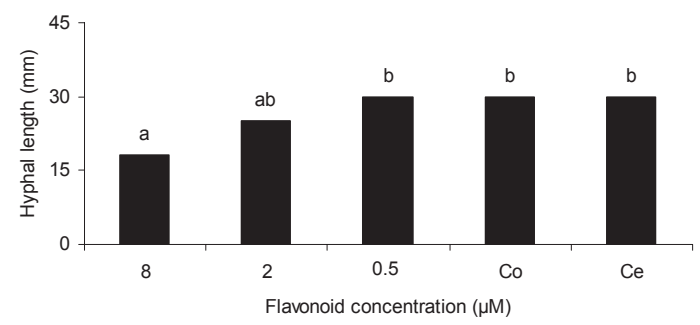

Gi. margarita

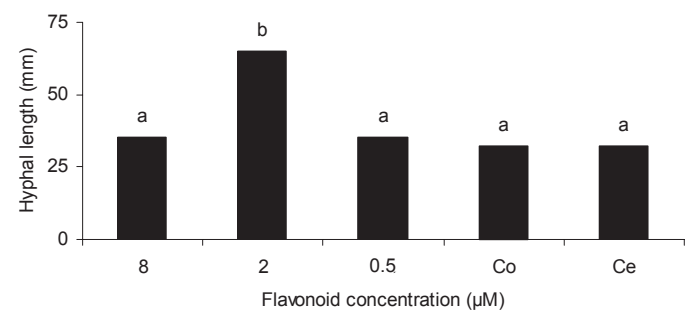

G. mosseae

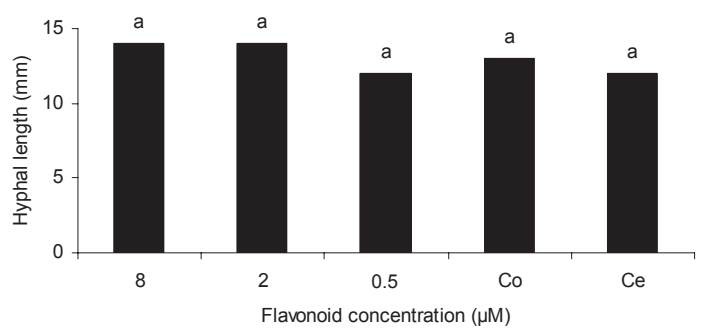

G. intraradices

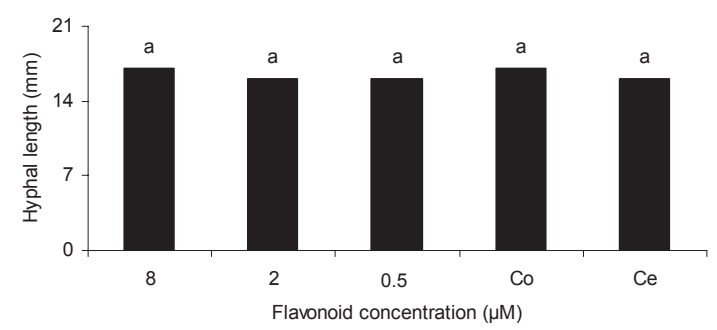

Figure 1: Effect of 3-methoxi-5,6,7,8-hydroxy-4'hydroxy flavone extracted from Trifolium repens, on the hyphal length (mm) of Gi. rosea, Gi. margarita, G. mosseae and $G$. intraradices spores. $\mathrm{Co}=\mathrm{Control}$ without flavonoids; $\mathrm{Ce}=\mathrm{Control}$ plus $0.05 \%$ ethanol. Values with the same letter are not significantly different as determined by Tukey's test $(\mathrm{P}<0.05)$ 
Effect of Trifolium repens flavonoids on arbuscular mycorrhiza, Scervino et al.

Gi. rosea

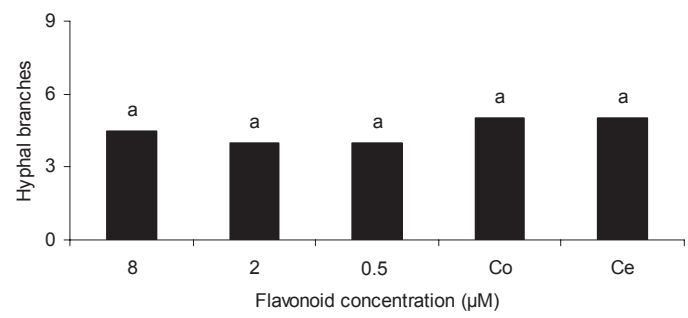

Gi. margarita

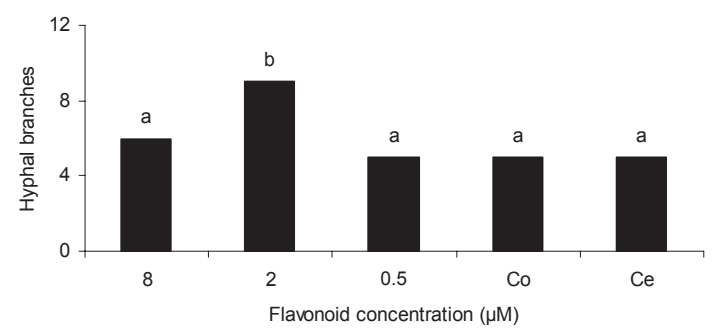

G. mosseae

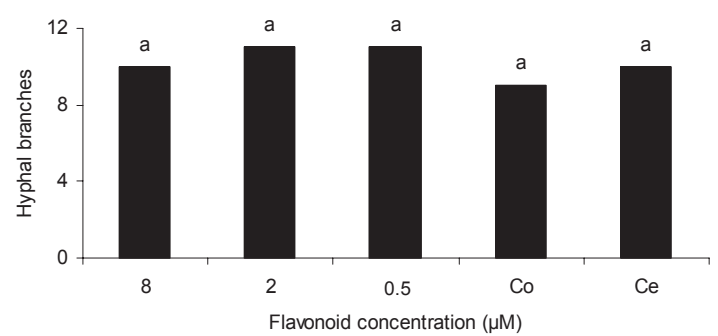

G. intraradices

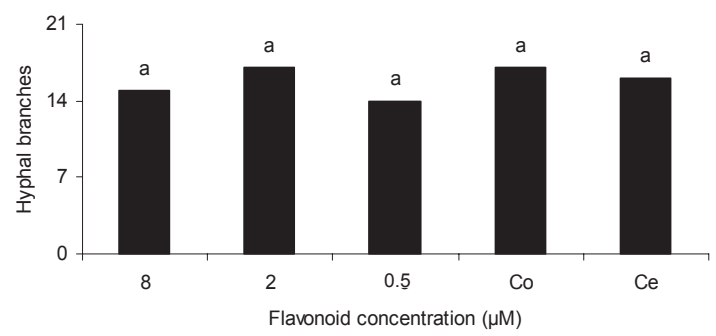

Figure 2: Effect of 3-methoxi-5,6,7,8-hydroxy-4'hydroxy flavone extracted from Trifolium repens, on the number of hyphal branches of Gi. rosea, Gi. margarita, G. mosseae and $G$. intraradices spores. $\mathrm{Co}=\mathrm{Control}$ without flavonoids; $\mathrm{Ce}=$ Control plus $0.05 \%$ ethanol. Values with the same letter are not significantly different as determined by Tukey's test $(\mathrm{P}<0.05)$ 


\section{DISCUSSION}

Plant flavonoids are metabolites implicated in the presymbiotic development of the AM fungi in soil and in the recognition process of plant-AM fungal interaction (Bécard and Piche, 1989; Paula and Siqueira, 1990; Vierheilig and Piche, 2002).

In the presymbiotic stage of the AM fungi, spore germination seems to be very sensitive to the action of flavonoids, especially those belonging to Gigaspora genus (Bécard et al., 1992; Chabot et al., 1992). None of the flavonoids isolated from clover shoot inhibited the percentage of germination of Gigaspora or Glomus species tested. It been reported that flavones had variable and even contradictory effects on the hyphal growth of Gigaspora spores (Vierheilig et al., 1998). The fact that the flavone NMHTV increased the hyphal length of Gi. margarita, while have inhibited that of $G i$. rosea reinforce this idea.

The concentrations of flavonoids seems to be important in their effect on AM fungi. It has been suggested that low concentration of flavonoids was more effective on the AM fungal growth (Tsai and Phillips, 1991; Bécard et al., 1992; Baptista and Siqueira, 1994). However, our results do not allow establishing a close relationship between the concentration of the flavonoids used and their effects on any of the steps of the presymbiotic stage of the Glomus and Gigaspora species tested.

The influence of flavonoids on the AM fungi seems to be different at genera level (Vierheilig et al., 1998). In our experiment we found that NMHTV had different effect not only at genera but also at the species level. None of the Glomus species tested were affected by any of the flavonoids assayed. However, the flavonoid NMHTV increased hyphal length, number of hyphal branches, number of clusters of auxiliary cells, number of entry points and the percentage of tomato root colonized by Gi. margarita, but did not affect these steps of development of Gi. Rosea.

Hyphal branching of the AM fungi has been described as one of the first event in host root recognition by the fungus during the presymbiotic phase (Giovannetti et al., 1996). The fact that $8 \mu \mathrm{M}$ of NMHTV inhibited hyphal length but not hyphal branching of $G i$. rosea indicated that hyphal branching, at least of Gi. rosea possibly requires a different stimulatory mechanisms or induction that does hyphal growth (Vierheilig et al., 1998). We found that NMHTV, which exhibit a hyphal length stimulating effect of $G i$. margarita, also enhanced hyphal branching and number of auxiliary cells of spores. These results suggest that this flavonoid have a more specific role on hyphal branching of Gigaspora independently on their effect on hyphal length. The flavonoid NMHTV also increased the number of entry points and the percentage of tomato root colonized by Gi. margarita. The importance of entry points on penetration, development into roots and effectiveness of the AM fungi has been described (Buee et al., 2000). A close relationship between the number of entry points and the percentage of root colonization reached by Gigaspora or Glomus symbionts in presence of the flavonoids tested was found. Our results suggest that the flavonoid NMHTV may influence the extension of $\mathrm{AM}$ colonization of roots mainly through its effects on the formation of entry points. 
Effect of Trifolium repens flavonoids on arbuscular mycorrhiza, Scervino et al.

Gi. rosea

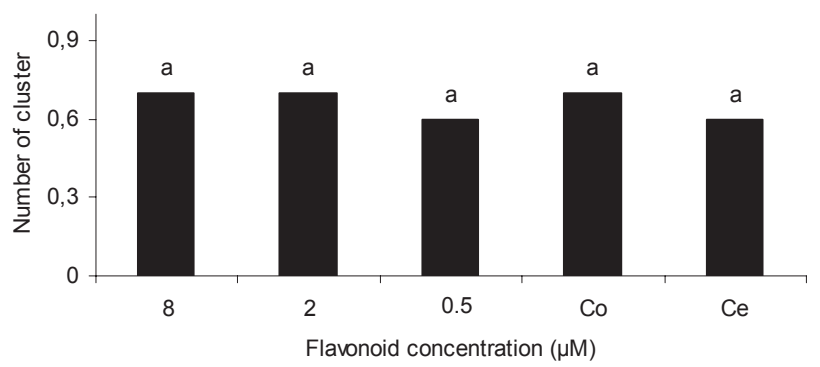

Gi. margarita

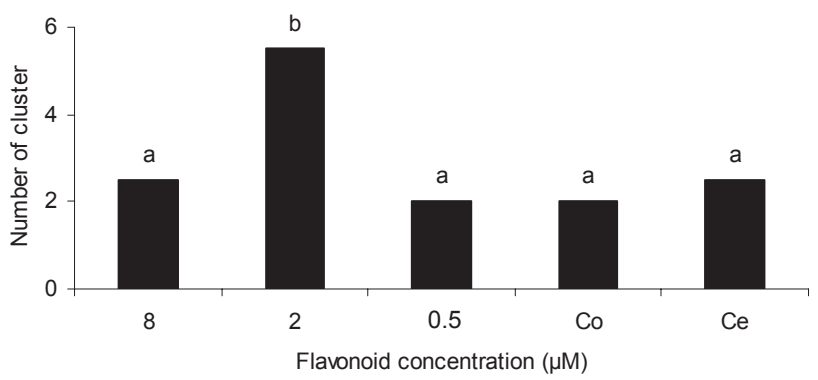

G. mosseae

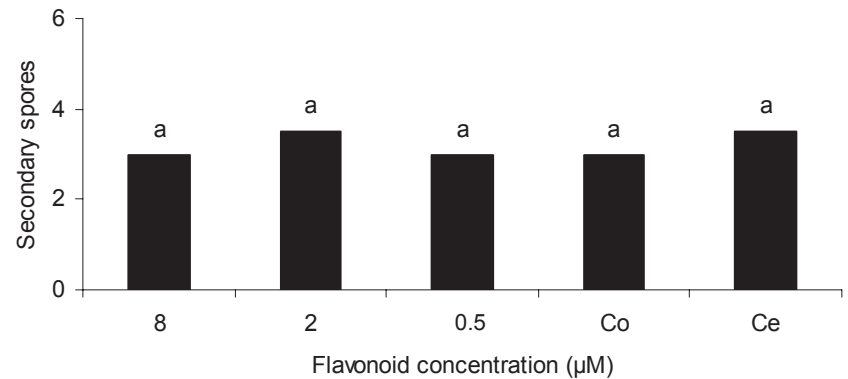

Figure 3: Effect of 3-methoxi-5,6,7,8-hydroxy-4'hydroxy flavone extracted from Trifolium repens, on the number of clusters of auxiliary cells of Gi. rosea, Gi. margarita, and on the number of secondary spores of $G$. mosseae spores. Co $=$ Control without flavonoids; $\mathrm{Ce}=\mathrm{Control}$ plus $0.05 \%$ ethanol. Values with the same letter are not significantly different as determined by Tukey's test $(\mathrm{P}<0.05)$ 
Gi. rosea

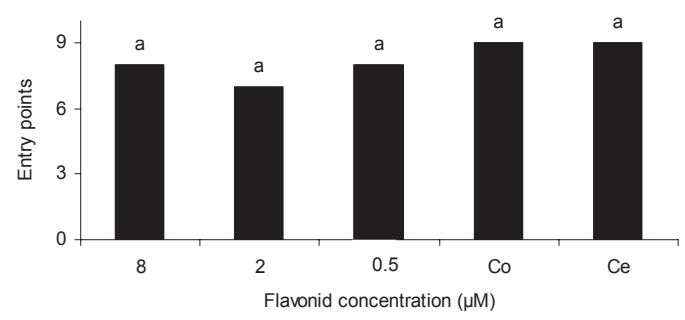

Gi. margarita

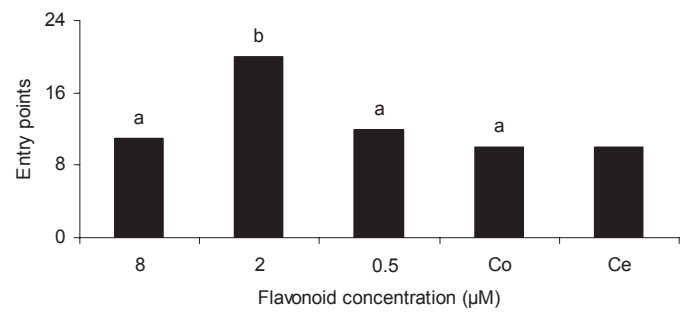

G. mosseae

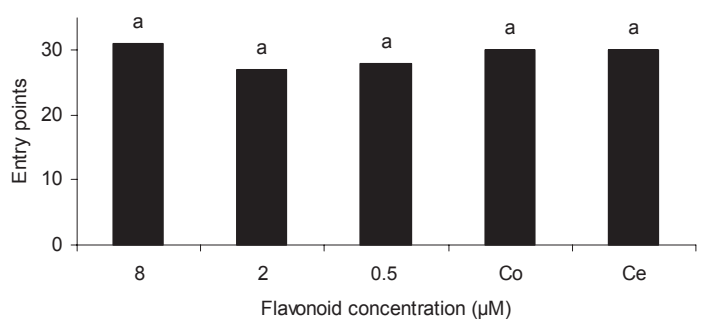

G. intraradices

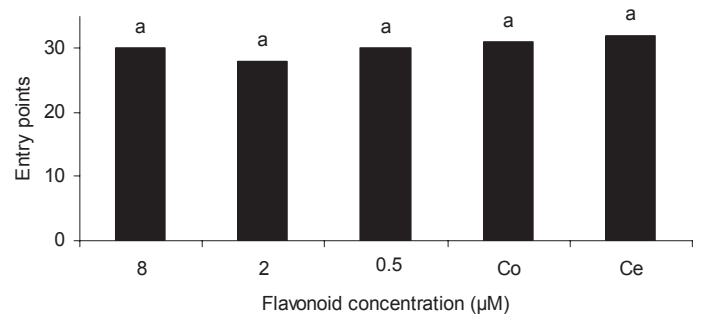

Figure 4: Effect of 3-methoxi-5,6,7,8-hydroxy-4'hydroxy flavone on the number of entry points per $30 \mathrm{~cm}$ of tomato root of Gi. rosea, Gi. margarita, G. mosseae and G. intraradices endophytes. $\mathrm{Co}=$ Control without flavonoids; $\mathrm{Ce}=$ Control plus $0.05 \%$ ethanol. Values with the same letter are not significantly different as determined by Tukey's test $(\mathrm{P}<0.05)$ 
Effect of Trifolium repens flavonoids on arbuscular mycorrhiza, Scervino et al.

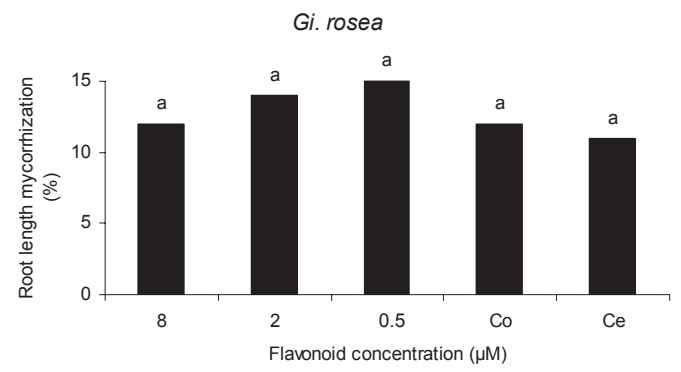

Gi. margarita

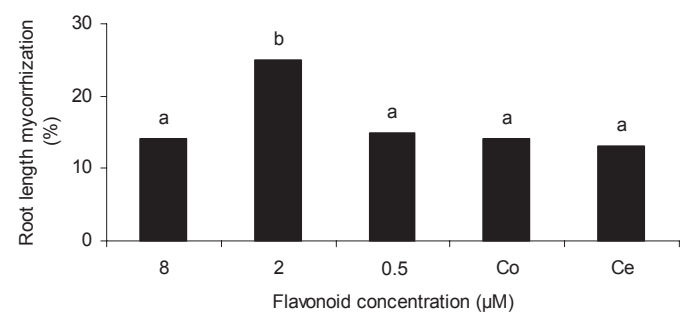

G. mosseae

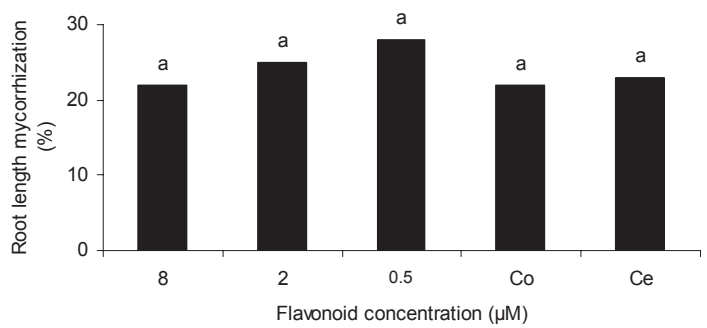

G. intraradices

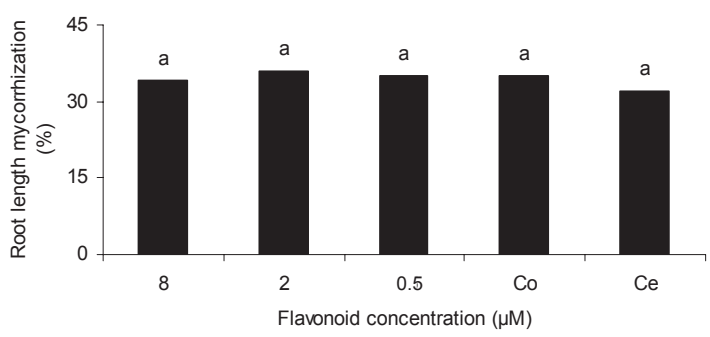

Figure 5: Effect of 3-methoxi-5,6,7,8-hydroxy-4'hydroxy flavone extracted from Trifolium repens, on the percentage of root colonization of tomato by Gi. rosea, Gi. margarita, G. mosseae and G. intraradices endophytes. Co $=$ Control without flavonoids; $\mathrm{Ce}=$ Control plus $0.05 \%$ ethanol. Values with the same letter are not significantly different as determined by Tukey's test $(\mathrm{P}<0.05)$ 
Plant secondary metabolites such as flavonoids might act as regulators in plant-fungus interactions during the precolonization and the cell-to-cell stage of the development of the symbiosis (Siqueira et al., 1991; Akiyama et al., 2002; Larose et al., 2002; Vierheilig et al., 2002). AM symbiosis have systemic influence in signals molecules implicated in plant susceptibility to AM formation (Vierheilig and Piche, 2002; Taylor and Harrier, 2003; Vierheilig et al., 2003). We observed stimulatory effects of the flavonoid NMHTV from shoot of non AM colonized plants not only on the presymbiotic stage of the fungus before that enters into the root but also during the penetration and development of the fungus Gi. margarita inside the roots. These results suggest the possible implication of this flavonoid in the susceptibility of tomato plant to the formation of AM symbiosis with this endophyte. This flavonoid synthesized in non AM colonized plant was not detected in plant colonized with the AM fungus and we also observed no synthesis of flavonoids in the shoots of clover that stimulated the AM symbiosis of tomato. On the other hand, exogenous application of the newly synthesized flavonoids in clover shoots after AM colonization did not stimulate the presymbiotic stages, the formation of AM penetration structures and the development of the fungus inside of the test plant root. This could mean that once the AM symbiosis is well established the observed suppression of further root colonization by AM fungi can be at least partially due to the disappearance of flavonoids that stimulated the AM symbiosis and to the formation of flavonoids which did not stimulate the formation and development of the AM symbiosis.

\section{ACKNOWLEDGEMENTS}

Financial support for this study was provided by the Comisión Interministerial de Ciencia y Tecnología, Spain and by UBACYT, ANCYPT and CONICET research programs from Argentina.

\section{REFERENCES}

Akiyama, K., Matsuoka, H., Hayashi, H. 2002. Isolation and identification of a phosphate deficiency-induced C-glycosylflavonoid that stimulates arbuscular mycorrhiza formation in melon roots. Molecular Plant Microbe Interaction. 15, 334-340.

Baptista, M.J., Siqueira, J.O. 1994. Efeito de flavonóides na germinação e no crescimento assimbiótico de fungos micorrízicos vesículoarbusculares. Revista Brasileira de Fisiologia Vegetal. 6, 127-134.

Bécard, G., Douds, D.D., Pfeffer, P.E. 1992. Extensive in vitro hyphal growth of vesiculararbuscular mycorrhizal fungi in the presence of $\mathrm{CO}_{2}$ and flavonols. Applied and Environmental Microbiology 58 821-825.

Bécard, G., Piche, Y. 1989. Fungal growth stimulation by $\mathrm{CO}_{2}$ and root exudates in vesicular-arbuscular mycorrhizal symbiosis. Applied and Environmental Microbiology. 55, 2320-2325.

Bentivenga, S.P., Morton, J.B. 1995. A monograph of the genus Gigaspora, incorporating developmental patterns of morphological characters. Mycologia. 87, 720732 .

Buee, M., Rossignol, M., Jauneau, A., Ranjeva, R., Becard, G. 2000. The pre-symbiotic growth of arbuscular mycorrhizal fungi is induced by a branching factor partially purified from plant root exudates. Molecular Plant Microbe Interaction. 13, 693-8. 


\section{Effect of Trifolium repens flavonoids on arbuscular mycorrhiza, Scervino et al.}

Chabot, S., Bel-Rhlid, T., Chenevert, R., Piche, Y. 1992. Hyphae growth promotion in vitro of the VA mycorrhizal fungus, Gigaspora margarita Becker and Hall, by the activity of structurally specific flavonoid compounds under $\mathrm{CO}_{2}$ enriched conditions. The New Phytologist. 122, 461-467.

Fracchia, S. 2002. Hongos saprotrofos del suelo como microorganismos auxiliares de la micorrización. Ph.D. Thesis, Universidad de Buenos Aires, Argentina.

Fracchia, S., Menendez, A., Godeas, A., Ocampo, J.A. 2001. A method to obtain monosporic cultures of arbuscular mycorrhizal fungi. Soil Biology and Biochemistry. 33, 12831285.

Gerdemann, J.W. 1955. Relation of a large soilborne spore to phycomycetous mycorrhizal infections. Mycologia. 47, 619-632.

Giovannetti, M., Mosse, B. 1980. An evaluation of techniques for measuring vesicular-arbuscular mycorrhizal infection in roots. The New Phytologist. 84, 489-500.

Giovannetti, M., Sbrana, C., Citernesi, A.S., Avio, L. 1996. Analysis of factor involved in fungal recognition responses to host-derived signals by arbuscular mycorrhizal fungi. The New Phytologist. 133, 65-71.

Harrison, M.J. 1998. Development of the arbuscular mycorrhizal symbiosis. Current Opinion Plant Biology. 1, 360-365.

Kape, R., Wex, K., Parniske, M., Görge, E., Wetzel, A., Werner, D. 1992. Legume root metabolites and VA-mycorrhiza development. Journal Plant Physiologist. 141, 54-60.

Larose, G., Chenevert, R., Moutoglis, P., Gagne, S., Piche, Y., Vierheilig, H. 2002. Flavonoid levels in roots of Medicago sativa are modulated by the developmental stage of the symbiosis and the root colonizing arbuscular mycorrhizal fungus. Journal of Plant Physiology. 159, 1329-1339.
Marsh, B.A.B. 1971. Measurement of length in random arrangements of lines. Journal of Applied Ecology. 8, 265-270.

Martin, J., Sampedro, I., Garcia-Romera, I., Garcia-Garrido, J.M., Ocampo, J.A. 2002. Arbuscular mycorrhizal colonization and growth of soybean (Glycine max) and lettuce (Lactuca sativa) and phytotoxic effects of olive mill residues. Soil Biology and Biochemistry. 34, 1769-1775.

Morandi, D. 1996. Occurrence of phytoalexins and phenolic compounds in endomycorrhizal interactions, and their potential role in biological control. Plant and Soil. 185, 241-251.

Morandi, D., Branzanti, B., GianinazziPearson, V. 1992. Effect of Some Plant Flavonoid on in Vitro Behavior of an Arbuscular Mycorrhizal Fungus. Agronomie. 12, 811-816.

Mosse, B. 1962. The establishment of vesicular arbuscular mycorrhiza under aseptic conditions. Journal General Microbiology. 27, 509-520.

Ocampo, J.A., Martin, J., Hayman, D.S. 1980. Influence of Plant Interactions on VesicularArbuscular Mycorrhizal Infections .1. Host and Non-Host Plants Grown Together. New Phytologist. 84, 27-35.

Paula, M.A., Siqueira, J.O. 1990. Stimulation of hyphal growthof the VA mycorrhizal fungus Gigaspora margarita by suspension-cultured Pueraria phaseoloides. New Phytologist. 115, 6975.

Phillips, D.A., Tsai, S.M. 1992. Flavonoids as plant signals to the rhizosphere microbes, Mycorrhiza. 1, 55-58.

Phillips, J.M., Hayman, D.S. 1970. Improved procedures for clearing roots and staining parasitic and vesicular-arbuscular mycorrhizal fungi for rapid assessment of infection. Transactions of the British Mycological Society. 55, 158-161. 
Ponce, M., Cervino, M., Erra-Balsells R, Ocampo JA, Godeas, A. 2004. Flavonoids from shoots and roots of Trifolium repens (white clover) grown in presence or absence of the arbuscular mycorrhizal fungus Glomus intraradices. Phytochemistry. 65, 3131-3134.

Poulin, M.J., Simard, J., Catford, J.G., Labrie, F., Piche, Y. 1997. Response of symbiotic endomycorrhizal fungi to estrogens and antiestrogens. Molecular Plant Microbe Interaction. 10, 481-487.

Poulton, J.L., Koide, R.T., Stephenson, A.G. 2002. Effects of mycorrhizal infection and high soil phosphorous improve vegetative growth and the female and male functions in tomato. The New Phytologist. 154, 255-264.

Siqueira, J.O., Safir, G.R., Nair, M.G. 1991. Stimulation of vesicular-arbuscular mycorrhiza Formation and growth of white clover by flavonoid compounds. The New Phytologist. 118, 87-93.

Taylor, J., Harrier, L.A. 2003. Expression studies of plant genes differentially expressed in leaf and root tissues of tomato colonised by the arbuscular mycorrhizal fungus Glomus mosseae. Plant Molecular Biology. 51, 619-629.
Tsai, S.M., Phillips, D.A. 1991. Flavonoids released naturally from alfalfa promote development of symbiotic Glomus spores in vitro. Applied and Environmental Microbiology. 57, 1485-1488.

Vierheilig, H., Bago, B., Albrecht, C., Poulin, M.J., Piche, Y. 1998. Flavonoids and arbuscular mycorrhizal fungi. Flavonoids in the Living System. 439, 9-33.

Vierheilig, H., Bago, B., Lerat, S., Piché, Y. 2002. Shoot-produced, light-dependent factors are partially involved in the expression of the arbuscular mycorrhizal (AM) status of AM host and non-host plants. Journal Plant Nutrition Soil Science. 165, 21-25.

Vierheilig, H., Lerat, S., Piche, Y. 2003. Systemic inhibition of arbuscular mycorrhiza development by root exudates of cucumber plants colonized by Glomus mosseae. Mycorrhiza. 13, 167-170.

Vierheilig, H., Piche, Y. 2002. Signalling in arbuscular mycorrhiza: Facts and hypotheses. Flavonoids in Cell Function. 505, 23-39. 